\title{
Oleic acid in the modulation of oocyte and preimplantation embryo development
}

\author{
Shabnam Fayezi², Jo L.M.R. Leroy ${ }^{3}$, Marefat Ghaffari Novin ${ }^{2}$ and Masoud Darabi \\ Faculty of Medicine, Shahid Beheshti University of Medical Sciences, Tehran, Iran; Veterinary Physiology and Biochemistry, \\ Department of Veterinary Sciences, University of Antwerp, Wilrijk, Belgium; and Drug Applied Research Center, Tabriz \\ University of Medical Sciences, Tabriz, Iran
}

Date submitted: 18.04.2017. Date revised: 22.08.2017. Date accepted: 20.09.2017

\section{Summary}

\begin{abstract}
Potential reproductive effects are considered as the major aspect of biomolecules functionality in an organism. The recent identification of differential patterns of fatty acids across ovarian follicles and their association with levels of sexual maturity highlights the importance of these biomolecules. It is well known that fatty acids are highly diverse in terms of their functional properties. Oleic acid is chemically classified as an unsaturated omega-9 fatty acid. Besides serving as an important energy source, oleic acid is involved in metabolic and structural roles. Free and esterified oleic acids are compartmentalized into discrete extracellular fluids, cell organelles and found within the cytosol. This review summarizes the current knowledge on the contribution of oleic acid in regulating female fertility, particularly its involvement in female germ cell growth and development. Oleic acid has been identified as a blastomeric and post-cryopreservation survival biomarker in bovine. Several related studies have shown the critical role of oleic acid in counteracting the detrimental effects of saturated fatty acids and in paracrine support of oocyte development. Although available data are not ideally detailed, most data suggest that oleic acid can contribute to normal oocyte and preimplantation embryo development via mechanisms involving metabolic partitioning of fatty acids, change in the membrane structural organization, attenuation of oxidative stress and regulation of intracellular signalling. Thus, oleic acid may play a significant role in oocyte and early embryo development, suggesting that future studies should explore in more detail its potential effects on the physiopathology of female reproduction.
\end{abstract}

Keywords: Desaturation, Embryo, Fatty acids, Fertilization, Ovary

\section{Introduction}

It is well known that fatty acids are highly diverse in terms of their metabolic and functional properties. Oleic acid (OlAc) is chemically classified as a longchain unsaturated omega-9 fatty acid (Fig. 1). Over the last decade large numbers of studies have suggested that the physiological role of OlAc extends beyond

\footnotetext{
${ }^{1}$ All correspondence to: Masoud Darabi. Drug Applied Research Center, Tabriz University of Medical Sciences, Tabriz 5165665811, Iran. Tel: +98 41 33363234. Fax +98 41 33363231. E-mail: darabim@tbzmed.ac.ir

${ }^{2}$ Department of Biology and Anatomical Sciences, Faculty of Medicine, Shahid Beheshti University of Medical Sciences, Tehran, Iran.

${ }^{3}$ Gamete Research Center, Veterinary Physiology and Biochemistry, Department of Veterinary Sciences, University of Antwerp, Wilrijk, Belgium.
}

that of an energy source and includes the regulation of cell metabolism, inflammation, tissue development and longevity (Lee \& Park, 2014; Han et al., 2017). A single cis double bond at the position $\Delta 9$ gives a high capability to OlAc to solubilize lipids (Robinson \& Cistola, 2014). Indeed, OlAc is a major determinant of plasma membrane fluidity (Funari et al., 2003), which is obviously associated with important functions including cell-cell interaction, membrane transport and signalling events. This fatty acid is capable of donating a hydrogen cation to an acceptor, and opposes oxidation or inhibits reactions brought about by dioxygen or peroxides (Choe \& Min, 2009). Moreover, OlAc can directly be attached to proteins, which is known as an important step in growth and differentiation of many cell types (Rios-Esteves \& Resh, 2013).

The main lipid classes of bovine oocytes are triglycerides, phospholipids, cholesteryl esters and free fatty acids (FFAs) which accounted, respectively, 


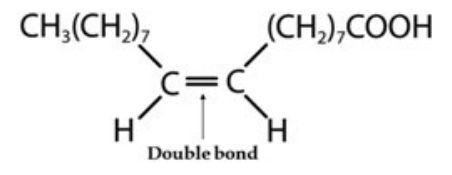

Figure 1 Oleic acid molecule. The organic structure of oleic acid has 18 carbons and a single cis configuration double bond on the ninth carbon (n-9 or $\omega-9)$ from the carboxyl (acid) end. This double bond is located at the centre of the molecule and causes a bend in the carbon chain which alters the physical properties and promotes fluidity. Derived from the Protein Data Bank ID: OLA. C, carbon; H, hydrogen; O, oxygen.

for $57.3,16.2,15.5$ and $10.9 \%$ of the total lipid extract (Kim et al., 2001). Free and esterified OlAc are metabolically regulated and compartmentalized into discrete extracellular fluids, cell organelles and within the cytosol. Oleic acid is a major monounsaturated fatty acid in the lipid extracts of bovine, sheep, porcine (Homa et al., 1986; Prates et al., 2013; Dunning et al., 2014) and human oocytes (Matorras et al., 1998), with relative proportions between 10 and $25 \%$ of total fatty acids. Moreover, the phospholipid fractions from oocytes of cattle and other ruminants contained even more OlAc ranging from 20 to $26 \%$ (Fig. 2).

Potential reproductive effects are considered as the major aspect of biomolecules functionality in an organism (Ströhle \& Döring, 2010). The recent identification of OlAc as a blastomeric and postcryopreservation survival biomarker in bovine may indicate the positive effects of this fatty acid on embryo development (González-Serrano et al., 2013; Ferreira et al., 2014). Other recent studies have shown the critical role of OlAc in paracrine supporting of oocyte development and in counteracting the detrimental effect of saturated fatty acids on oocyte development. The association between fertilization and fatty acids in general has been reviewed previously (McKeegan \& Sturmey, 2011; Dunning et al., 2014). However, to date, there has been no dedicated review of the literature dealing specifically with potential role of OlAc in reproduction.

This review will summarize current knowledge on the role of OlAc in the modulation of oocyte and preimplantation embryo development. We will focus primarily on changes in female sex hormones production, follicular development and early embryo development that are relevant to future clinical studies.

\section{Oleic acid in endocrine-related reproduction function}

Fatty acids may act more generally and indirectly via actions in the central nervous system to alter peripheral organ function. For instance, long-term control of food intake is affected by circulating OlAc in ruminants (Ingvartsen \& Andersen, 2000).

\section{Pituitary control}

While dietary OlAc and linoleic acid (LnAc) caused no change in basal luteinizing hormone (LH), these long-chain fatty acids reduced gonadotropin-releasing hormone-induced LH release in dairy cows (Salehi et al., 2015). Despite the fact that the physiological significance of these effects on cattle ovulation remains to be investigated, these results suggest that concentration of circulating OlAc is important in the neuroendocrine control of reproduction, which appears to be independent of hypothalamic function and directly modulates gonadotropin release from the pituitary.

\section{Steroidogenesis}

The follicle cells and the corpus luteum in the ovary secrete the female sex hormones estrogen and progesterone, respectively, which regulate ovulation and control the reproductive cycle. These functions appear to be related to cellular fatty acid status. Notably, the amounts of unsaturated fatty acids including OlAc were significantly greater in minor plasma membrane phospholipids of the corpus luteum in pregnant ewes than in regressing corpus luteum of non-pregnant ewes at day 13 of the estrous cycle (Zelinski et al., 1988). This selective increase in the OlAc content of membrane phospholipids reflects dynamic changes in OlAc partitioning during the reproductive cycle. In addition to dietary intake, OlAc is supplied by a fine regulated de novo synthesis mechanism (Fig. 3). Endogenous synthesis of OlAc is primarily regulated by stearoyl-coenzyme A desaturase (SCD) in multiple cell types, including follicular cells (Feuerstein et al., 2007; Aardema et al., 2017; Fayezi et al., 2017). A recent study showed that prepubertal heifers versus cows had higher levels of SCD gene expression in granulosa cells and OlAc in follicular fluid (Warzych et al., 2017). Moreover, SCD activity was profoundly increased by follicle-stimulating hormone ( $\mathrm{FSH})$, which initiates and supports follicular development and regulates steroidogenesis in females (Moreau et al., 2006).

Free OlAc supplementation at an amount of $200 \mu \mathrm{M}$ to the maturation medium of bovine cumulus-oocyte complexes (COC) significantly increased estradiol production, although no effect was found on progesterone (Maya-Soriano et al., 2013). Vanholder et al. (2005) also reported that a 2.5-fold higher free OlAc $(500 \mu \mathrm{M})$, such as stearic acid and palmitic acid, stimulated estradiol secretion of bovine granulosa cells, while simultaneously inhibiting cell proliferation. A relatively lower concentration of OlAc $(300 \mu \mathrm{M})$ also inhibited human granulosa cell proliferation (Mu et al., 2001). It is of note 

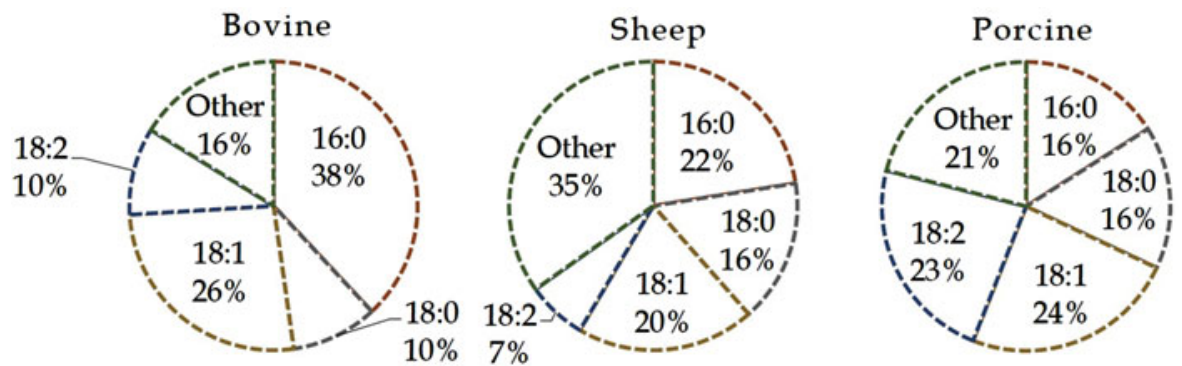

Figure 2 Fatty acid composition in phospholipids from bovine, sheep and porcine oocytes. Data of bovine are the average from Zeron et al. (2001) and McEvoy et al. (2000) studies. Other parts are based on data of Homa et al. (1986). 16:0, palmitic acid; 18:0, stearic acid; $18: 1$, oleic acid; $18: 2$, linoleic acid.

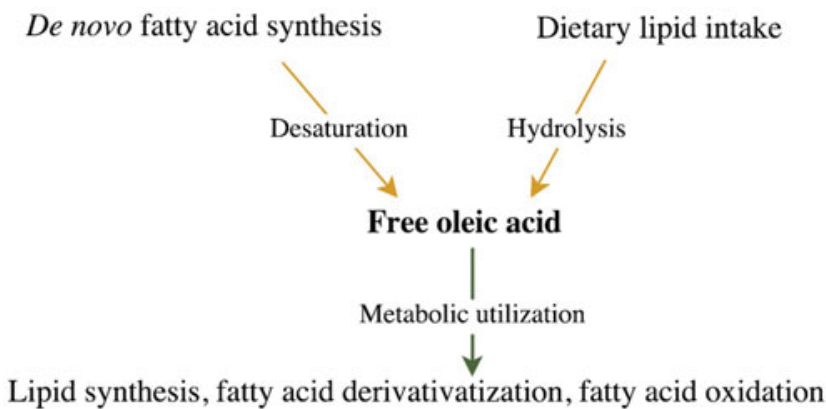

Figure 3 Diagram illustrating the metabolic pathways for oleic acid. Free oleic acid is derived from dietary lipid intake or endogenous de novo production. The latter is dependent to desaturation reaction, which is a rate-limiting step in the oleic acid synthesis. Oleic acid can be incorporated into cellular lipids, metabolized into bioactive derivatives or catabolized to release energy.

that all of these OlAc concentrations are 3-fold to 7.8fold higher than the follicular fluid value of $\sim 64 \mu \mathrm{M}$ (Jungheim et al., 2011) and are also in 1.5-fold to 2.3-fold excess of the free OlAc in plasma. In a later study, these fatty acids individually did not reproduce such effects on bovine theca cells (Vanholder et al., 2006). Such cell type-specific differences may be attributed to an in vivo adaptation process that modulates cellular sensitivity to FFAs. This hypothesis was confirmed by a more recent study, which reported decreases in estradiol and progesterone along with the gonadotropin hormone receptors following long-term (8 day) OlAc incubation in a serum-free, immature bovine granulosa cell culture model (Yenuganti et al., 2016). It has been suggested that OlAc-induced changes are due to a reduced response to gonadotropic hormones (Yenuganti et al., 2016). However, because OlAc increased estradiol secretion in short-term cultures of mature bovine granulosa cells (Vanholder et al., 2006), it rather appears to be due to cell-specific adaptive responses. Consistently, theca cells are more directly supplied with blood, which is rich in FFAs (Vanholder et al., 2006).
Altogether, these data underscore the dynamic changes occurring in the OlAc content of follicles during the reproductive cycle, which can modulate steroidogenesis.

\section{Oleic acid in formation of competent oocytes}

A unique diversity of lipid molecular compounds has been documented for oocytes. For instance, a more complex lipid composition was recorded during the in vitro maturation process of porcine oocytes (Pirro et al., 2014). The knowledge accumulated regarding the effect of OlAc on follicular development and measures of oocyte developmental competence, including maturation and fertilization rate, is discussed further below. Table 1 summarizes data related to cattle, as the most studied species.

\section{Follicular fluid}

The free fatty acid fraction in bovine (Leroy et al., 2005) and human (Valckx et al., 2014a) sera and ovarian follicular fluid is rich in palmitic acid, stearic acid and OlAc. The concentration of individual FFA in human serum was reflected in follicular fluid, but overall the relationship was weak (Jungheim et al., 2011). Notably, human follicular fluid showed an increase of $3.3 \%$ in stearic acid and a reduction of $-7.0 \%$ in OlAc relative to serum (Jungheim et al., 2011). These data suggest that a selective transport mode determines OlAc concentration in follicular fluid. This selective transport may be accompanied by other metabolites, as evidenced in the placental transport of OlAc coupled with amino acids in primary human trophoblasts (Lager et al., 2013). Hudson et al. (2014) have shown that in a low amino acid environment the physiological concentration of OlAc, but not palmitic acid or stearic acid, caused a reduction in fluorescence dye transfer from bovine cumulus cells to the oocyte. The expression of connexin proteins, as the main 
Table 1 Effect of oleic acid supplementation on cumulus-granulosa cell function, oocyte characteristics and embryo development in cattle

\begin{tabular}{|c|c|c|c|}
\hline Model & Main findings & Potential mechanism & Reference \\
\hline \multicolumn{4}{|l|}{ Dietary intake (IVF) } \\
\hline $\begin{array}{l}800 \text { g/day, } \\
\text { OlAc-enriched high-fat } \\
\text { versus low-fat diet }\end{array}$ & $\uparrow$ IVM and ED in vitro & $\begin{array}{l}\uparrow \text { Cell ingredients; } \downarrow \\
\text { Adverse effects of } \\
\text { insulin }\end{array}$ & $\begin{array}{l}\text { (Fouladi-Nashta et al., } \\
\text { 2007) }\end{array}$ \\
\hline \multicolumn{4}{|l|}{ Dietary intake } \\
\hline $\begin{array}{l}1.35-1.50 \% \text {, Sunflower } \\
\text { oil }\end{array}$ & $\uparrow$ Retrieved oocytes, CR and ED & $\uparrow$ Essential nutrients & (Bilby et al., 2006) \\
\hline \multicolumn{4}{|l|}{ COC culture } \\
\hline $\begin{array}{l}200 \mu \mathrm{M}, \text { OlAc combined } \\
\text { with SFA versus stearic } \\
\text { acid }\end{array}$ & $\begin{array}{l}\downarrow \text { IVM and CR; } \uparrow \text { Reduced } \\
\text { glutathione, LD in blastocysts and } \\
\text { cryotolerance }\end{array}$ & $\downarrow$ Oxidative stress & $\begin{array}{l}\text { (Van Hoeck et al., 2013; } \\
\quad \text { Van Hoeck et al., 2015) }\end{array}$ \\
\hline $500 \mu \mathrm{M}$ & $\uparrow$ Steroidogenesis & $\begin{array}{l}\uparrow \text { Membrane stability, } \\
\text { free cholesterol }\end{array}$ & (Vanholder et al., 2005) \\
\hline $80-200 \mu \mathrm{M}$ & $\begin{array}{l}\leftrightarrow \text { Apoptosis in GC, FR, CR and } \\
\text { blastocyst yield }\end{array}$ & - & $\begin{array}{l}\text { (Leroy et al., 2005; Nandi } \\
\text { et al., 2014) }\end{array}$ \\
\hline $200 \mu \mathrm{M}$ & $\begin{array}{l}\leftrightarrow \text { Developmental competence and } \\
\text { total blastocyst cell number }\end{array}$ & - & (Van Hoeck et al., 2011) \\
\hline $200 \mu \mathrm{M}$ & $\begin{array}{l}\uparrow \text { Steroidogenesis; } \leftrightarrow \text { Progesterone } \\
\text { and cytoplasmic maturation; } \downarrow \text { IVM }\end{array}$ & - & $\begin{array}{l}\text { (Maya-Soriano et al., } \\
\text { 2013) }\end{array}$ \\
\hline 40 and $160 \mu \mathrm{M}$ & $\begin{aligned} \leftrightarrow & \text { Developmental competence and } \\
& \text { proliferation of GC }\end{aligned}$ & - & (Nandi et al., 2014) \\
\hline $\begin{array}{l}100 \mathrm{mg} / \mathrm{ml} \\
\text { OlAc-enriched } \\
\text { phospholipids }\end{array}$ & $\uparrow \mathrm{CR}$ and blastocyst formation & $\downarrow$ Transition temperature & (Zeron et al., 2002) \\
\hline $500 \mu \mathrm{M}, \mathrm{OlAc}$ & $\uparrow$ FR, post-fertilization development & $\uparrow$ Energy storage & $\begin{array}{l}\text { (Leroy et al., 2003; } \\
\quad \text { Aardema et al., 2011) }\end{array}$ \\
\hline $1000 \mu \mathrm{M}, \mathrm{OlAc}$ & $\downarrow$ Proliferation of GC, FR, CR and ED & $\uparrow$ Membrane formation & (Jorritsma et al., 2004) \\
\hline \multicolumn{4}{|l|}{ GV culture } \\
\hline $\begin{array}{l}100 \mu \mathrm{M}, \text { OlAc versus } \\
\text { SFA and linoleic acid }\end{array}$ & $\uparrow$ Breakdown rate and MII & $\downarrow$ Adenylate cyclase & (Homa \& Brown, 1992) \\
\hline \multicolumn{4}{|l|}{ Fertilized oocytes culture } \\
\hline $100-1000 \mu \mathrm{M}$ & $\uparrow \mathrm{CR}$ and $\mathrm{ED}$ & $\downarrow$ Oxidative stress & $\begin{array}{l}\text { (Karaşahin \& Arikan, } \\
\text { 2015) }\end{array}$ \\
\hline
\end{tabular}

${ }^{*} \mathrm{COC}$, cumulus-oocyte complex; CR, cleavage rate; d, days; ED, embryo development; FR, fertilization rate; GC, cumulus-granulosa cells; GV, germinal vesicles; IVM, in vitro maturation rate; LD, lipid droplets; MII, metaphase II oocytes; OlAc, oleic acid; SFA, saturated fatty acids. $\downarrow$, significant decrease; $\uparrow$, significant increase; $\leftrightarrow$ no significant change.

structural components of gap junctions, has been considered to be modulated by nutrients (Hudson et al., 2014). These data support the hypothesis that OlAc in the follicle microenvironment can contribute to the regulation of metabolite transport through the control of gap junctional communication between cumulus cells and the developing oocyte.

Fatty acid composition and glucose content in follicular fluid appear to be generally involved in follicular development (Warzych et al., 2014). Notably, OlAc in follicular fluid was related to a higher bovine oocyte quality, in terms of COC morphology and follicular diameter (Warzych et al., 2014). However, the fatty acid composition of follicular fluid was not associated with bovine (Sinclair et al., 2008) or human (O'Gorman et al., 2013) oocyte cleavage following in vitro fertilization (IVF). In another study, the concentration of palmitic acid and stearic acid in human follicular fluid was associated with morphologically poor and good COCs, respectively (Sinclair et al., 2008). In a clinical study, we have reported that the number of mature oocytes from women undergoing IVF cycle was inversely associated with total saturated fatty acid content of phospholipids in follicular fluid (Shaaker et al., 2012). Associations between phospholipid OlAc and the number of retrieved mature oocytes showed a positive trend (Shaaker et al., 2012). Moreover, a higher concentration of total saturated and a lower concentration of total unsaturated fatty acids were found in patients with cleavage failure $\left(\mathrm{O}^{\prime}\right.$ Gorman et al., 2013). Intrafollicular OlAc concentration is significantly increased in phospholipid fraction while 
showing a reduction in the non-esterified fatty acids fraction as bovine follicles become dominant (Renaville et al., 2010). Follicular fluid of women with higher body mass index and lower IVF outcome showed increased phospholipid content (Fayezi et al., 2014) but reduced concentration of OlAc in the phospholipid fraction (Valckx et al., 2014a). These observations argued for a link between relative ratio of OlAc/other fatty acids in follicular fluid phospholipids and oocyte development.

\section{Follicular growth}

A recent study using high-resolution mass spectrometry technique demonstrated that the fatty acid patterns of porcine follicles were largely different from non-follicular ovarian tissue (Uzbekova et al., 2015). Moreover, porcine follicles were heterogeneous in their lipid composition, possibly reflecting changes in fatty acids over the natural course of ovarian folliculogenesis (Uzbekova et al., 2015). More recently, Warzych et al. (2017) have shown that sexual maturity in bovine alters the follicular environment with regard to the lipid droplet content within the oocyte and follicular fluid fatty acid composition. Overall, these data further support the idea that dynamic change in fatty acid content of follicular compartments contributes to regulating female gametogenesis. Several studies, which are discussed below, point to the specific effect of OlAc on the process of follicular growth.

Diet supplementation with long-chain fatty acids has been shown to increase the ovulation rate, the number of follicles and serum progesterone in ewes (El-Shahat \& Abo-El Maaty, 2010). However, depending on the type of fatty acid used in the diet, the effect on oocyte development can be very different (Leroy et al., 2014). Consistent with this hypothesis, more oocytes were collected from dairy cows fed OlAc as compared with cows fed trans OlAc, LnAc or linolenic acid (Bilby et al., 2006).

Follicular growth and antrum formation in bovine are affected by elevated FFAs concentrations in vitro (Van Hoeck et al., 2014; Valckx et al., 2015). Moreover, experimental data support the idea that FFAs not only modulate final oocyte maturation, but also potentially interfere with follicular growth at the early stages of development (Leroy et al., 2015). The same manner as in vivo, however, depending on the type and ratio of fatty acids the final effect may be different (Leroy et al., 2015). The diameter of in vitro-cultured murine follicles was higher and apoptosis markers in luteinized granulosa cells were reduced with OlAc treatment $(210 \mu \mathrm{M})$, compared with high stearic acid (Valckx et al., 2014b). In addition, when OlAc was used in combination with stearic acid and palmitic acid these differences were eliminated (Valckx et al., 2014b). Furthermore, in a rat model, the FSH/FSH receptor pathway in granulosa cells that triggers ovarian follicular growth from primordial stage involves the activation of de novo OlAc synthesis as a downstream consequence (Moreau et al., 2006). Finally, a more complete understanding of the role of OlAc in follicular growth will require developing new strategies that focus on earlier stages of gametogenesis, including primordial germ cell specification and proliferation.

\section{Oocyte quality and fertilization}

Post-fertilization events such as the formation of zygote and embryogenesis are considered as markers for developmental capacity of oocytes. It has long been suggested that the polyunsaturated fatty acid (PUFA) supplements can beneficially affect fertility (Wathes et al., 2007). Although PUFA-enriched diet increased dominant follicle size in dairy cows and OlAc-enriched diet increased recovery rate of oocytes, no significant additional beneficial effects were seen between OlAcand PUFA-enriched diets with respect to oocyte quality as characterized by subsequent embryo development (Bilby et al., 2006). Compared with a low-fat diet, a high-fat diet containing mainly palmitic acid and OlAc resulted in significantly improved developmental potential of oocytes in lactating dairy cows, as evidenced by increased rate of blastocyst production and quality during IVF, possibly through enhanced biosynthesis of cell ingredients and neutralizing the adverse effects of insulin (Fouladi-Nashta et al., 2007).

Although a $100 \mu \mathrm{M}$ dose of albumin-bound OlAc did not show a statistically significant difference compared with the control albumin alone, the breakdown rate of bovine germinal vesicles and oocyte progression to MII were higher after incubation with OlAc as compared with palmitoleic acid, stearic acid and LnAc, possibly due to a specific activation of adenylate cyclase (Homa \& Brown, 1992). Moreover, LnAc significantly inhibited in vitro bovine cumulus cell expansion and decreased the percentage of oocytes at MII stage in a dose-dependent manner (Marei et al., 2010). Although maturation rate was not affected, incubation with $500 \mu \mathrm{M}$ albumin-bound OlAc during in vitro maturation significantly increased the percentage of bovine oocytes that were fertilized (Aardema et al., 2011). However, adding both saturated fatty acids palmitic acid and stearic acid reversed these effects. Furthermore, OlAc reversed the detrimental effects of palmitic acid and stearic acid (Aardema et al., 2011). Free stearic acid was much more potent than the combined OlAc, palmitic acid and stearic acid to increase the expression of genes related to apoptosis and oxidative stress, including $\mathrm{Bcl}$-2-associated $\mathrm{X}$ protein $(B A X)$, glutathione peroxidase 1 (GPX1) and superoxide dismutase 1 (SOD1), in bovine oocytes 
and luteinized granulosa cell cultures (Van Hoeck et al., 2013; Valckx et al., 2014b). However, the expression level of the proliferation-related gene growth arrest and DNA-damage-inducible (GADD45B) was increased after treatment with $210 \mu \mathrm{M}$ OlAc (Van Hoeck et al., 2015). In addition, the glutathione content of bovine oocytes and the number of lipid droplets in the resulting morulae were lower following high stearic acid treatment compared with that of combined saturated fatty acids and OlAc (Van Hoeck et al., 2015). These observations were attributed to the compensating action of OlAc.

A few studies have shown no significant effect at lower doses of free OlAc alone compared with vehicle control. OlAc at concentrations equivalent to that of FFAs in postpartum cows follicular fluid $(200 \mu \mathrm{M})$ showed no effect (Leroy et al., 2005) on in vitro maturation, fertilization and cleavage rate and blastocyst yield. Despite significant increasing effect on cumulus cell steroidogenesis, exposure to a $200 \mu \mathrm{M}$ concentration of OlAc resulted in no beneficial effects on cytoplasmic maturation, and nuclear maturation of heifer oocytes (Maya-Soriano et al., 2013). In contrast to palmitic and stearic acid, OlAc at concentrations between 40 and $160 \mu \mathrm{M}$ showed no detrimental effect on bovine oocyte maturation rate and subsequent fertilization rate and embryo yield as well as on granulosa cell growth (Nandi et al., 2014). These data further highlight the importance of the ultimate OlAc ratio of the cellular lipids, over the entire quantity, which needs to be taken into account in future studies.

Concentration and form of OlAc supplementation in the growth medium may also determine the effect on the developmental capacity of oocytes. Albuminbound OlAc at a high concentration equivalent to plasma FFAs in postpartum cows $(1 \mathrm{mM})$ reduced the proliferation of granulosa cells, in vitro fertilization and subsequent cleavage and embryo development (Jorritsma et al., 2004). However, the study did not distinguish between supplementation alone with albumin and the control condition. Thus, besides the high concentration, these adverse effects can be caused by addition of albumin alone (Leroy et al., 2005, 2008). Notably, incomplete extraction of fatty acids from albumin has been postulated as a possible explanation for variations in embryo formation rate with different concentrations of albumin (Cagnone \& Sirard, 2014). In contrast, a previous study showed that a high dose of albumin-bound OlAc $(1.25 \mathrm{mM})$ was the most effective treatment among other unsaturated fatty acids for promoting rat embryos development to blastocyst stage (Khandoker \& Tsujii, 1999). Other studies have shown that a lower amount of OlAc $(500 \mu \mathrm{M})$ exerts a promoting effect on oocyte developmental competence post-fertilization (Leroy et al., 2003; Aardema et al., 2011), possibly by increasing lipid storage in bovine oocyte (Aardema et al., 2011). In addition, OlAc prevents suppression of post-fertilization development induced by saturated fatty acids in bovine (Aardema et al., 2011; Van Hoeck et al., 2011). It has been hypothesized that OlAc may mitigate the negative effects induced by saturated fatty acids. As evidenced in bovine oocytes (Aardema et al., 2011) and in hamster ovary cells (Listenberger et al., 2001), co-exposure to OlAc resulted in the metabolic channelling of palmitic and stearic acid into the non-toxic lipid droplets.

Altogether, these results suggest that the ultimate effect of free OlAc on oocyte in vitro maturation (IVM) is determined by the relative ratio of cellular OlAc to other fatty acids. While no consensus has been reached regarding the effect of OlAc alone on IVM, it is evident that OlAc counteracts the detrimental consequences of exposure to saturated fatty acids during IVM.

The efficient metabolic incorporation of OlAc by bovine oocyte has been demonstrated by altered lipid droplets (Aardema et al., 2011), energy metabolismrelated gene expression, and mitochondrial function and ultrastructure (Van Hoeck et al., 2013) following exposure to OlAc during IVM. The physical properties and thermal responses of the plasma membrane remarkably changed during the process of oocyte maturation. A study performed using Fourier transform infrared analysis detected a large difference in membrane lipid phase transition temperature among human germinal vesicles, mature (MII) oocytes and zygotes (Ghetler et al., 2005). The higher phase transition temperature in zygotes may reflect differences in the fatty acids within the membrane phospholipids. Indeed, a high ratio of OlAc to saturated fatty acids reduced the transition temperatures of lipids and increased membrane fluidity in animal oocytes (Arav et al., 2000; Zeron et al., 2001). Electrofusion of bovine COCs with liposomes prepared from egg phosphatidylcholine with a high content of OlAc decreased transition temperature and increased blastocyst formation in vitro (Zeron et al., 2002). Bovine GV-stage oocytes were much more susceptible to cryoinjury than mature oocytes and embryos (Arav et al., 1996). Interestingly, the fusion of large membrane fragments from mature oocytes with bovine GV oocytes membrane enhanced their chilling resistance (Arav et al., 1996). Notably, in contrast with palmitic acid and stearic acid, no adverse effect on the embryo cryotolerance was observed with OlAc treatment during in vitro maturation of bovine oocytes (Shehab-El-Deen et al., 2009). These observations were attributed to alteration in the membrane lipid composition. Because of the large capacity of OlAc to solubilize lipids (Robinson \& Cistola, 2014), such potential changes in OlAc will profoundly affect cell membrane function.

The lower bovine fertility during summer than winter is attributed to disrupted development of 
oocyte due to heat stress (Rivera \& Hansen, 2001). Notably, OlAc reaches $38 \%$ of total fatty acids and became the most abundant fatty acid in membrane phospholipids of bovine germinal vesicle oocytes during winter, an increase of $28 \%$ as compared with the summer season (Zeron et al., 2001). This compositional change generally modifies physical properties of membranes, such as melting temperature (Zeron et al., 2001). Such a process may be involved in increased oocyte quality in winter. Whether there is any change in the plasma membrane fatty acids during the oocyte maturation remains to be determined.

As noted earlier, the concentrations of fatty acids, including OlAc, in follicular fluid and oocyte quality potential were intimately correlated in bovine (Warzych et al., 2017). According to these results, during the prepubertal period de novo synthesis of fatty acids, as the main energy resources in ovarian follicles, is low and insufficient to fully support oocyte development (Warzych et al., 2017). A study on human cumulus-granulosa cells has demonstrated that SCD activity is required for cumulus cell lipid storage and steroidogenesis (Fayezi et al., 2017). In addition, oocyte maturation was negatively affected by SCD inhibition in cumulus-granulosa cells, possibly due to deficient lipid-mediated paracrine support. Subsequently, these effects were rescued by supplementation of the main product of SCD OlAc, confirming the idea that its de novo production in cumulus cells contributes to the acquisition of oocyte meiotic and developmental competence during folliculogenesis (Fayezi et al., 2017). It is interesting to note that de novo synthesis and paracrine release of OlAc by astrocytes induced neuronal differentiation (Tabernero et al., 2001). This function was mediated by the activation of protein kinase C (Tabernero et al., 2001), which is known to promote oocyte maturation and early embryo development (Mondadori et al., 2008; Tepekoy et al., 2014). In addition, Aardema et al. (2017) have shown that treatment of SCD inhibitor plus stearic acid during IVM led to a decrease in the SCD activity index in cumulus cells, as well as a reduction in the number of produced blastocysts. The authors attributed these findings to the protective effect of SCD against saturated fatty acids via conversion to unsaturated fatty acids. Taken together, a sufficient accessibility of metabolic processes to OlAc and its relative amount to the cell fatty acid content are particularly important in oocyte maturation.

\section{Oleic acid in preimplantation embryo development}

Embryo cleavage and blastocyst formation or hatching are the main stages of early embryogenesis. The ratio of various fatty acids is an important metabolic feature and may strongly influence reproductive outcomes. The relative percentage of OlAc markedly increased during the developmental stages of bovine (Menezo et al., 1982) and rabbit (Yahia Khandoker et al., 1998) embryos. Consistent with these data, OlAc and LnAc were more abundant in the late preimplantation stage human embryos (Haggarty et al., 2006). These observations can reflect a differential pattern of fatty acid uptake during embryo development which may be conserved among species. Indeed, at later developmental stages, a trend towards increasing uptake of OlAc (Wang \& Tsujii, 1999; Haggarty et al., 2006) and LnAc (Haggarty et al., 2006) over palmitic acid was seen in human and mouse embryos. In addition, during preimplantation embryo development the channelling of exogenous OlAc was preferentially directed towards phospholipids and away from intermediate energy substrates such as triglycerides (Wang \& Tsujii, 1999). According to these data, active uptake and metabolic channelling of OlAc towards phospholipids can contribute to early embryo development.

The data obtained from phosphosphingolipidome analysis showed increased concentration of phosphatidylcholine classes containing OlAc (3.8-fold), LnAc (4.5-fold) and linolenic acid (3-fold) for in vivo produced compared with in vitro produced bovine embryos (Sudano et al., 2012). Moreover, phosphatidylethanolamines, ceramides (Ferreira et al., 2014) and cholesteryl ester (González-Serrano et al., 2013) containing primarily OlAc have been identified as blastomeric biomarkers for bovine embryo quality using ionization mass spectrometry approach. Indeed, in vivo produced bovine blastocysts showed higher concentrations of OlAc in phospholipids and cholesteryl-ester fractions compared with their in vitro derived counterparts (González-Serrano et al., 2013). Accordingly, unsaturated fatty acid content may be an important factor in the post-cryopreservation survival of in vivo (Sudano et al., 2012) and in vitro (Pereira et al., 2007) produced bovine embryos. Moreover, a diet fed to cows enriched in LnAc compromised the embryo cryotolerance and decreased the hatching rate of in vivo produced embryos (Guardieiro et al., 2014). Therefore, it appears that among unsaturated fatty acids, a beneficial effect is produced by OlAc on embryo cryotolerance.

Hatching rate of bovine blastocyst in a culture supplemented with $0.1 \%$ serum lipid fraction tended to be lower compared with total serum-containing medium. This lipid fraction was extracted using ether, a nonpolar solvent capable of extracting major lipid classes. Compositional analysis showed that this fraction had a fatty acid concentration comparable with total serum. However, it contained significantly reduced concentrations of $\mathrm{OlAc}$ and increased amounts 
of palmitic acid and stearic acid compared with total serum (Cagnone \& Sirard, 2014). Nevertheless, a largescale gene expression analysis of bovine blastocysts failed to detect differences in transcriptome following these in vitro culture conditions (Cagnone \& Sirard, 2014). These results suggest that posttranscriptional modifications may be responsible for the changes in the embryo development upon serum lipid, particularly OlAc, supplementation.

Based on previous evidence for the association between unsaturated fatty acid content and cryopreservation success of embryos (Shehab-El-Deen et al., 2009; Sudano et al., 2012), an in vitro study demonstrated that supplementation of bovine embryo culture medium with OlAc at a concentration of $1.0 \mathrm{mM}$ increased the rates of embryonic cleavage, development and quality (Karaşahin \& Arikan, 2015).

Stinshoff et al. (2014) have observed that conjugated LnAc significantly suppressed the expression of $S C D$, a key enzyme for de novo OlAc synthesis, and resulted in reduced bovine embryo development in vitro, a phenotype very similar to when mouse embryos (Ben-David et al., 2013) were exposed to selective inhibitors of SCD. The requirement for LnAc, as another abundant unsaturated fatty acid, in embryo development is controversial. Only limited positive effects on in vitro embryonic development and quality were observed in bovine by supplementation of LnAc (Karaşahin \& Arikan, 2015). Remarkably, treatment of mouse pronuclear and 2-cell stages with albuminbound PUFAs including LnAc resulted in a significantly lower percentage of cleaved embryos and blastocysts (Nonogaki et al., 1994). Consistent with these results, the treatment of bovine COCs with LnAc, even at a concentration not affecting oocyte maturation (50 mM), significantly decreased subsequent cleavage and blastocyst rates (Marei et al., 2010). These adverse effects were accompanied by a sharp increase in the arachidonic acid-dependent pro-inflammatory pathway (Marei et al., 2010). In agreement to these findings, a reduced arachidonic acid content in bovine oocytes was associated with the improved quality of derived embryo without an increase in oocyte maturation or embryo production rates (Lapa et al., 2011).

Overall, the current data from in vitro models suggested that OlAc supplementation may beneficially effect embryo development that is obviously distinct from other bioactive fatty acids like LnAc and arachidonic acid.

\section{Potential mechanism of reproductive function of oleic acid in female}

A general weakness in the most studies reviewed lay in their observational nature, which did not allow mechanistic insights into the reproductive role of fatty acids, in particular OlAc. Nevertheless, current knowledge suggests that potential mechanisms underlying association of OlAc with female reproduction may include altered metabolic channelling, plasma membrane fluidity, oxidative stress and intracellular signalling events (Fig. 4).

The division from one to four blastomeres requires a large increase in membrane surface area, as much as 1.74-fold (Pratt \& George, 1989). Oleic acid is a major fatty acid in membrane phospholipids (Homa et al., 1986; Kim et al., 2001; Zeron et al., 2001) and is essential for organization and normal function of membrane (for review see Lopez et al., 2014). The functional significance of OlAc in membrane formation at the earliest stages of zygote development remains to be investigated.

Oleic acid activates proliferative and maturational signalling pathways in which protein kinase $C$ participates (Tabernero et al., 2001). In light of the information available on the critical role of protein kinase $C$ in bovine oocyte maturation and early embryo development (Mondadori et al., 2008), OlAc may be considered as an important regulator of reproduction acting at the level of a common signalling pathway. This aspect of reproduction control by OlAc will require further study, which will help to deal with conflicting viewpoints.

Advanced lipidomics analyses point to prostaglandins and cannabinoids as markers for female fertility (Vilella et al., 2013a; Agirregoitia et al., 2015). Metabolism of OlAc and omega- 6 fatty acids also known as n-6 PUFAs - shares common enzymatic pathway steps catalyzed by desaturases and prostaglandin-endoperoxide synthases (Cheng et al., 2015). Therefore, OlAc can modify PUFA metabolism and, subsequently, prostaglandin and cannabinoids synthetic pathways. Indeed, OlAc significantly increased the ratio of prostaglandin E2 to prostaglandin $\mathrm{F} 2 \alpha$ produced by endometrial cells isolated from the late pregnant ewes (Cheng et al., 2015). Such change in prostaglandin ratio has been associated with embryo implantation in human (Vilella et al., 2013b) and fetal maturation in porcine (Cao et al., 2005; Ziecik et al., 2008), which may similarly contribute to ovarian folliculogenesis or granulosa cell differentiation.

Conceiving and sustaining a pregnancy to term are the most reliable markers for oocyte quality and embryo competence. This aspect has been particularly examined in the study of dietary PUFAs. Indeed, feeding PUFAs dynamically during the postpartum period increased the occurrence of pregnancy in cattle (Silvestre et al., 2011; Dirandeh et al., 2013). Regarding dietary OlAc, this point has not been studied. 


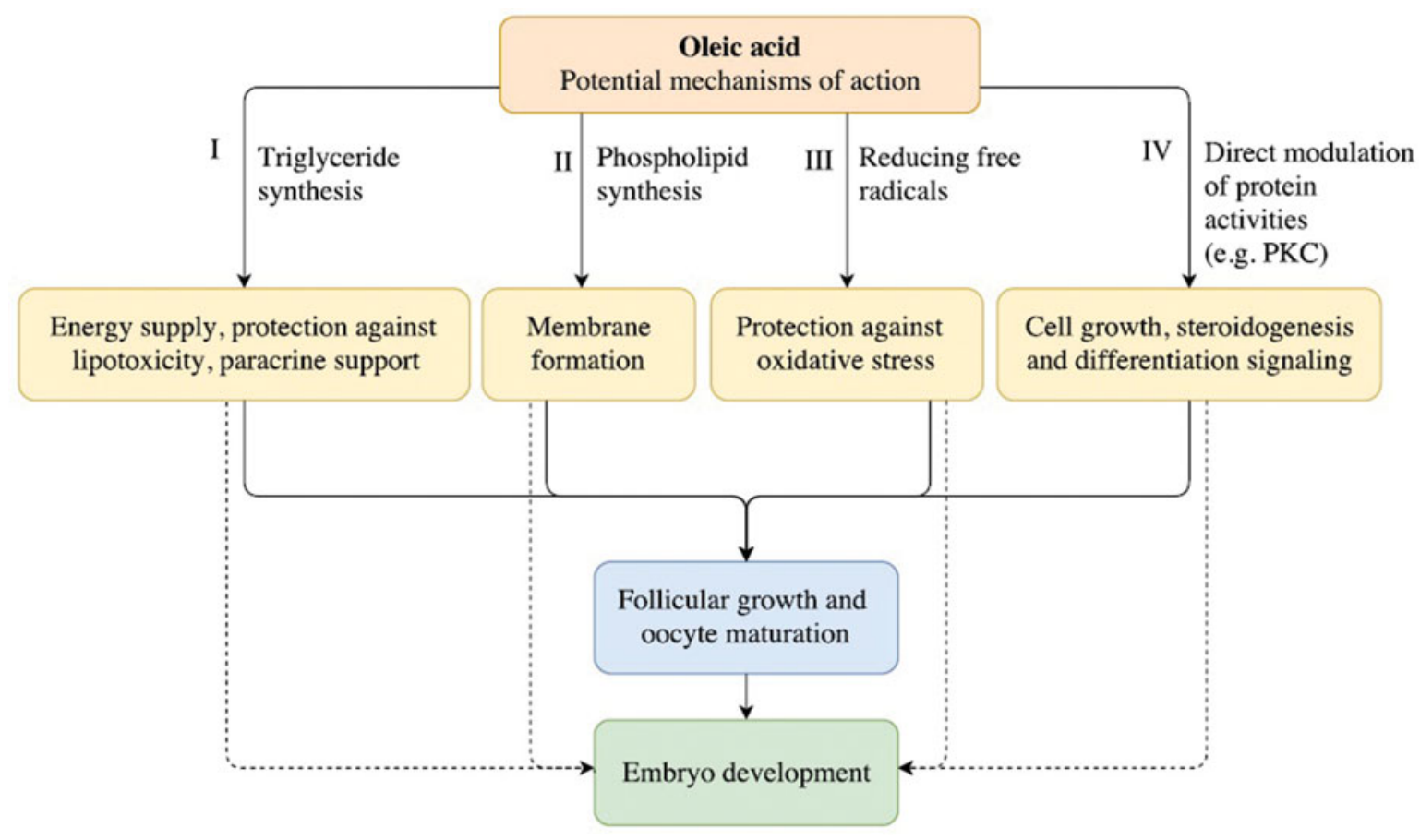

Figure 4 Potential mechanisms underlying the effects of oleic acid on ovarian function and embryo development. The additive effects on embryo development are shown in dot-dash lines. Oleic acid profoundly increases partitioning of fatty acids towards lipid droplet which in turn serves as energy supply and protects oocytes and granulosa cells against lipotoxicity, and enhances lipid-mediated paracrine support of oocytes (I). Oocyte plasma membrane fluidity and cell divisions at the early stages of embryo development can be modified by oleic acid-promoted phospholipid synthesis (II). Oleic acid can influence follicular metabolic activities, steroidogenesis and oocyte development either directly by acting as a regulator of cellular signalling via the modulation of oxidative stress (III) and the activation of protein kinase C (PKC) (IV).

\section{Conclusions}

Although available data are not ideally detailed, most studies suggest that dietary or de novo synthesis of OlAc contributes to the acquisition of developmental competence by oocytes and to early stages of embryo development in mammals. The beneficial effects of OlAc may involve one or more of the following possible mechanisms. Firstly, OlAc profoundly increased the partitioning of fatty acids towards lipid droplet which in turn not only protects oocytes and granulosa cells against lipotoxicity but also may promote the lipid-mediated paracrine support of oocytes by surrounding cells. Secondly, OlAc acts as a major determinant of plasma membrane structural organization in follicular cells. Thirdly, OlAc acts directly as a metabolic component or regulator of oxidative stress and cellular signalling. Therefore, this monounsaturated fatty acid may play a significant role in oocyte and early embryo development, suggesting that future studies should explore in more detail its potential effects on physiopathology of female reproduction.

\section{Acknowledgements}

This work was supported by the Drug Applied Research Center at Tabriz University of Medical Sciences (grant number \#93/710) and Shahid Beheshti University of Medical Sciences (grant number \#1393-191-13033). Shabnam Fayezi is recipient of a grant from the interdisciplinary PhD programme in the National Elites Foundation (2015-2018).

\section{Authors' contributions}

S.F. wrote the manuscript and made the figures. J.L., M.G.N. and M.D. contributed to the manuscript writing and editing. All authors read and approved the final manuscript.

\section{Declaration of interest}

The authors declare that they have no competing interests. 


\section{References}

Aardema, H., van Tol, H.T.A., Wubbolts, R.W., Brouwers, J.F.H.M., Gadella, B.M. \& Roelen, B.A.J. (2017). StearoylCoA desaturase activity in bovine cumulus cells protects the oocyte against saturated fatty acid stress. Biol. Reprod. 96, 982-92.

Aardema, H., Vos, P.L.A.M., Lolicato, F., Roelen, B.A.J., Knijn, H.M., Vaandrager, A.B., Helms, J.B. \& Gadella, B.M. (2011). Oleic acid prevents detrimental effects of saturated fatty acids on bovine oocyte developmental competence. Biol. Reprod. 85, 62-9.

Agirregoitia, E., Ibarra-Lecue, I., Totorikaguena, L., Mendoza, R., Expósito, A., Matorras, R., Urigüen, L. \& Agirregoitia, N. (2015). Dynamics of expression and localization of the cannabinoid system in granulosa cells during oocyte nuclear maturation. Fertil. Steril. 104, 753-60.

Arav, A., Pearl, M. \& Zeron, Y. (2000). Does membrane lipid profile explain chilling sensitivity and membrane lipid phase transition of spermatozoa and oocytes? Cryo Letters 21, 179-86.

Arav, A., Zeron, Y., Leslie, S.B., Behboodi, E., Anderson, G.B. \& Crowe, J.H. (1996). Phase transition temperature and chilling sensitivity of bovine oocytes. Cryobiology 33, 58999.

Ben-David, U., Gan, Q.-F., Golan-Lev, T., Arora, P., Yanuka, O., Oren, Y.S., Leikin-Frenkel, A., Graf, M., Garippa, R., Boehringer, M., Gromo, G. \& Benvenisty, N. (2013). Selective elimination of human pluripotent stem cells by an oleate synthesis inhibitor discovered in a highthroughput screen. Cell Stem Cell 12, 167-79.

Bilby, T.R., Block, J., do Amaral, B.C., Sa Filho, O., Silvestre, F.T., Hansen, P.J., Staples, C.R. \& Thatcher, W.W. (2006). Effects of dietary unsaturated fatty acids on oocyte quality and follicular development in lactating dairy cows in summer. J. Dairy Sci. 89, 3891-903.

Cagnone, G. \& Sirard, M.A. (2014). The impact of exposure to serum lipids during in vitro culture on the transcriptome of bovine blastocysts. Theriogenology 81, 712-22.

Cao, J., Yosida, M., Kitazawa, T. \& Taneike, T. (2005). Uterine region-dependent differences in responsiveness to prostaglandins in the non-pregnant porcine myometrium. Prostaglandins Other Lipid Mediat. 75(1-4), 10522.

Cheng, Z., Abayasekara, D.R.E., Elmes, M., Kirkup, S. \& Wathes, D.C. (2015). Effect of oleic acid supplementation on prostaglandin production in maternal endometrial and fetal allantochorion cells isolated from late gestation ewes. Placenta 36, 1011-7.

Choe, E. \& Min, D.B. (2009). Mechanisms of antioxidants in the oxidation of foods. Compr. Rev. Food Sci. Food Saf. 8, 34558.

Dirandeh, E., Towhidi, a., Zeinoaldini, S., Ganjkhanlou, M., Pirsaraei, Z.A. \& Fouladi-Nashta, A. (2013). Effects of different polyunsaturated fatty acid supplementations during the postpartum periods of early lactating dairy cows on milk yield, metabolic responses, and reproductive performances. J. Anim. Sci. 91, 713-21.

Dunning, K.R., Russell, D.L. \& Robker, R.L. (2014). Lipids and oocyte developmental competence: the role of fatty acids and $\beta$-oxidation. Reproduction 148, R15-27.
El-Shahat, K.H. \& Abo-El Maaty, A.M. (2010). The effect of dietary supplementation with calcium salts of long chain fatty acids and/or L-carnitine on ovarian activity of Rahmani ewes. Anim. Reprod. Sci. 117, 78-82.

Fayezi, S., Darabi, M., Nouri, M., Rahimipour, A. \& Mehdizadeh, A. (2014). Analysis of follicular fluid total phospholipids in women undergoing in-vitro fertilisation. J. Obstet. Gynaecol. 34, 259-62.

Fayezi, S., Ghaffari Novin, M., Darabi, M., Norouzian, M., Nouri, M., Farzadi, L. \& Darabi, M. (2017). Primary culture of human cumulus cells requires stearoyl-coenzyme a desaturase 1 activity for steroidogenesis and enhancing oocyte in vitro maturation. Reprod. Sci. [Epub ahead of print]

Ferreira, M.S., de Oliveira, D.N., Gonçalves, R.F. \& Catharino, R.R. (2014). Lipid characterization of embryo zones by silica plate laser desorption ionization mass spectrometry imaging (SP-LDI-MSI). Anal. Chim. Acta 807, 96102.

Feuerstein, P., Cadoret, V., Dalbies-Tran, R., Guerif, F., Bidault, R. \& Royere, D. (2007). Gene expression in human cumulus cells: one approach to oocyte competence. Hum. Reprod. 22, 3069-77.

Fouladi-Nashta, A.A., Gutierrez, C.G., Gong, J.G., Garnsworthy, P.C. \& Webb, R. (2007). Impact of dietary fatty acids on oocyte quality and development in lactating dairy cows. Biol. Reprod. 77, 9-17.

Funari, S.S., Barceló, F. \& Escribá, P.V (2003). Effects of oleic acid and its congeners, elaidic and stearic acids, on the structural properties of phosphatidylethanolamine membranes. J. Lipid Res. 44, 567-75.

Ghetler, Y., Yavin, S., Shalgi, R. \& Arav, A. (2005). The effect of chilling on membrane lipid phase transition in human oocytes and zygotes. Hum. Reprod. 20, 3385-9.

González-Serrano, A.F., Pirro, V., Ferreira, C.R., Oliveri, P., Eberlin, L.S., Heinzmann, J., Lucas-Hahn, A., Niemann, H. \& Cooks, R.G. (2013). Desorption electrospray ionization mass spectrometry reveals lipid metabolism of individual oocytes and embryos. PLoS One 8, e74981.

Guardieiro, M.M., Machado, G.M., Bastos, M.R., Mourão, G.B., Carrijo, L.H.D., Dode, M.A.N., Leroy, J.L.M.R. \& Sartori, R. (2014). A diet enriched in linoleic acid compromises the cryotolerance of embryos from superovulated beef heifers. Reprod. Fertil. Dev. 26, 511-20.

Haggarty, P., Wood, M., Ferguson, E., Hoad, G., Srikantharajah, A., Milne, E., Hamilton, M. \& Bhattacharya, S. (2006). Fatty acid metabolism in human preimplantation embryos. Hum. Reprod. 21, 766-73.

Han, S., Schroeder, E.A., Silva-García, C.G., Hebestreit, K., Mair, W.B. \& Brunet, A. (2017). Mono-unsaturated fatty acids link H3K4me3 modifiers to C. elegans lifespan. Nature 544(7649), 185-90.

Van Hoeck, V., Rizos, D., Gutierrez-Adan, A., Pintelon, I., Jorssen, E., Dufort, I., Sirard, M.A., Verlaet, A., Hermans, N., Bols, P.E.J. \& Leroy, J.L.M.R. (2015). Interaction between differential gene expression profile and phenotype in bovine blastocysts originating from oocytes exposed to elevated non-esterified fatty acid concentrations. Reprod. Fertil. Dev. 27, 372-84.

Homa, S.T. \& Brown, C.A. (1992). Changes in linoleic acid during follicular development and inhibition of 
spontaneous breakdown of germinal vesicles in cumulusfree bovine oocytes. J. Reprod. Fertil. 94, 153-60.

Homa, S.T., Racowsky, C. \& McGaughey, R.W. (1986). Lipid analysis of immature pig oocytes. J. Reprod. Fertil. 77, 42534.

Hudson, N.L., Berg, M.C., Green, M.P., Back, P.J., Thorstensen, E.B., Peterson, A.J., Pitman, J.L. \& McNatty, K.P. (2014). The microenvironment of the ovarian follicle in the postpartum dairy cow: Effects on reagent transfer from cumulus cells to oocytes in-vitro. Theriogenology 82, 563-73.

Ingvartsen, K.L. \& Andersen, J.B. (2000). Integration of metabolism and intake regulation: a review focusing on periparturient animals. J. Dairy Sci. 83, 1573-97.

Jorritsma, R., César, M.L., Hermans, J.T., Kruitwagen, C.L.J.J., Vos, P.L.A.M. \& Kruip, T.A.M. (2004). Effects of nonesterified fatty acids on bovine granulosa cells and developmental potential of oocytes in vitro. Anim. Reprod. Sci. 81, 225-35.

Jungheim, E.S., MacOnes, G.A., Odem, R.R., Patterson, B.W., Lanzendorf, S.E., Ratts, V.S. \& Moley, K.H. (2011). Associations between free fatty acids, cumulus oocyte complex morphology and ovarian function during in vitro fertilization. Fertil. Steril. 95, 1970-4.

Karaşahin, T. \& Arikan, Ş. (2015). The effect of oleic and linoleic acids on in vitro bovineembryonic development and embryo quality. Turk. J. Vet. Anim. Sci. 39, 154-9.

Khandoker, M.A.M.Y. \& Tsujii, H. (1999). Effect of exogenous fatty acids on in vitro development of rat embryos. Asian Australas. J. Anim. Sci. 12, 169-73.

Kim, J.Y., Kinoshita, M., Ohnishi, M. \& Fukui, Y. (2001). Lipid and fatty acid analysis of fresh and frozenthawed immature and in vitro matured bovine oocytes. Reproduction 122, 131-8.

Lager, S., Gaccioli, F., Ramirez, V.I., Jones, H.N., Jansson, T. \& Powell, T.L. (2013). Oleic acid stimulates system A amino acid transport in primary human trophoblast cells mediated by Toll-like receptor 4. J. Lipid Res. 54, 725-33.

Lapa, M., Marques, C.C., Alves, S.P., Vasques, M.I., Baptista, M.C., Carvalhais, I., Silva Pereira, M., Horta, A.E.M., Bessa, R.J.B. \& Pereira, R.M. (2011). Effect of trans-10 cis-12 conjugated linoleic acid on bovine oocyte competence and fatty acid composition. Reprod. Domest. Anim. 46, 904-10.

Lee, H. \& Park, W.J. (2014). Unsaturated fatty acids, desaturases, and human health. J. Med. Food 17, 189-97.

Leroy, J.L.M. R., Van Soom, A., Opsomer, G. \& Bols, P.E.J. (2008). The consequences of metabolic changes in highyielding dairy cows on oocyte and embryo quality. Animal 2, 1120-7.

Leroy, J.L.M.R., Sturmey, R.G., Van Hoeck, V., De Bie, J., McKeegan, P.J. \& Bols, P.E.J. (2014). Dietary fat supplementation and the consequences for oocyte and embryo quality: hype or significant benefit for dairy cow reproduction? Reprod. Domest. Anim. 49, 353-61.

Leroy, J.L.M.R., Vanholder, T., Mateusen, B., Christophe, A., Opsomer, G., de Kruif, A., Genicot, G. \& Van Soom, A. (2005). Non-esterified fatty acids in follicular fluid of dairy cows and their effect on developmental capacity of bovine oocytes in vitro. Reproduction 130, 485-95.

Leroy, J., Valckx, S.D.M., Jordaens, L., De Bie, J., Desmet, K.L.J., Van Hoeck, V., Britt, J.H., Marei, W.F. \& Bols, P.E.J.
(2015). Nutrition and maternal metabolic health in relation to oocyte and embryo quality: critical views on what we learned from the dairy cow model. Reprod. Fertil. Dev. 27, 693-703.

Leroy, J., Vanholder, T., Van Soom, A., Opsomer, G., Bols, P. \& de Kruif, A. (2003). Effect of oleic acid during in vitro maturation and fertilisation, first cleavage and embryo development of bovine cumulus-oocytecomplexes. Reprod. Domest. Anim. 38, 328.

Listenberger, L.L., Ory, D.S. \& Schaffer, J.E. (2001). Palmitateinduced apoptosis can occur through a ceramideindependent pathway. J. Biol. Chem. 276, 14890-5.

Lopez, S., Bermudez, B., Montserrat-De La Paz, S., Jaramillo, S., Varela, L.M., Ortega-Gomez, A., Abia, R. \& Muriana, F.J.G. (2014). Membrane composition and dynamics: A target of bioactive virgin olive oil constituents. Biochim. Biophys. Acta 1838, 1638-56.

Marei, W.F., Wathes, D.C. \& Fouladi-Nashta, A.A. (2010). Impact of linoleic acid on bovine oocyte maturation and embryo development. Reproduction 139, 979988.

Matorras, R., Ruiz, J.I., Mendoza, R., Ruiz, N., Sanjurjo, P. \& Rodriguez-Escudero, F.J. (1998). Fatty acid composition of fertilization-failed human oocytes. Hum. Reprod. 13, 222730.

Maya-Soriano, M.J., Taberner, E. \& López-Béjar, M. (2013). Retinol improves in vitro oocyte nuclear maturation under heat stress in heifers. Zygote 21, 377-84.

McEvoy, T.G., Coull, G.D., Broadbent, P.J., Hutchinson, J.S. \& Speake, B.K. (2000). Fatty acid composition of lipids in immature cattle, pig and sheep oocytes with intact zona pellucida. J. Reprod. Fertil. 118, 163-70.

McKeegan, P.J. \& Sturmey, R.G. (2011). The role of fatty acids in oocyte and early embryo development. Reprod. Fertil. Dev. 24, 59-67.

Menezo, Y., Renard, J.P., Delobel, B. \& Pageaux, J.F. (1982). Kinetic study of fatty acid composition of day 7 to day 14 cow embryos. Biol. Reprod. 26, 787-90.

Mondadori, R.G., Neves, J.P. \& Gonçalves, P.B. (2008). Protein kinase $\mathrm{C}$ (PKC) role in bovine oocyte maturation and early embryo development. Anim. Reprod. Sci. 107, $20-9$.

Moreau, C., Froment, P., Tosca, L., Moreau, V. \& Dupont, J. (2006). Expression and regulation of the SCD2 desaturase in the rat ovary. Biol. Reprod. 74, 75-87.

Mu, Y.M., Yanase, T., Nishi, Y., Tanaka, A., Saito, M., Jin, C.H., Mukasa, C., Okabe, T., Nomura, M., Goto, K. \& Nawata, H. (2001). Saturated FFAs, palmitic acid and stearic acid, induce apoptosis in human granulosa cells. Endocrinology 142, 3590-7.

Nandi, S., Tripathi, S.K., Farman, M., Gupta, P.S.P. \& Mondal, S. (2014). Effect of non-esterified fatty acids on oocyte and granulosa cell growth in vitro. J. Agroecol. Nat. Resour. Manag. 1, 29-31.

Nonogaki, T., Noda, Y., Goto, Y., Kishi, J. \& Mori, T. (1994). Developmental blockage of mouse embryos caused by fatty acids. J. Assist. Reprod. Genet. 11, 482-8.

O'Gorman, a, Wallace, M., Cottell, E., Gibney, M.J., McAuliffe, F.M., Wingfield, M. \& Brennan, L. (2013). Metabolic profiling of human follicular fluid identifies potential biomarkers of oocyte developmental competence. Reproduction 146, 389-95. 
Pereira, R.M., Baptista, M.C., Vasques, M.I., Horta, A.E.M., Portugal, P.V., Bessa, R.J.B., Silva, J.C., Pereira, M.S. \& Marques, C.C. (2007). Cryosurvival of bovine blastocysts is enhanced by culture with trans-10 cis-12 conjugated linoleic acid (10t,12c CLA). Anim. Reprod. Sci. 98(3-4), 293301.

Pirro, V., Oliveri, P., Ferreira, C.R., González-Serrano, A.F., Machaty, Z. \& Cooks, R.G. (2014). Lipid characterization of individual porcine oocytes by dual mode DESI-MS and data fusion. Anal. Chim. Acta 848, 51-60.

Prates, E.G., Alves, S.P., Marques, C.C., Baptista, M.C., Horta, A.E.M., Bessa, R.J.B. \& Pereira, R.M. (2013). Fatty acid composition of porcine cumulus oocyte complexes (COC) during maturation: effect of the lipid modulators trans-10, cis-12 conjugated linoleic acid (t10,c12 CLA) and forskolin. In Vitro Cell. Dev. Biol. Anim. 49, 335-45.

Pratt, H.P.M. \& George, M.A. (1989). Organisation and assembly of the surface membrane during early cleavage of the mouse embryo. Roux's Arch. Dev. Biol. 198, 170-8.

Renaville, B., Bacciu, N., Comin, A., Motta, M., Poli, I., Vanini, G. \& Prandi, A. (2010). Plasma and follicular fluid fatty acid profiles in dairy cows. Reprod. Domest. Anim. 45, 118-21.

Rios-Esteves, J. \& Resh, M.D. (2013). Stearoyl CoA desaturase is required to produce active, lipid-modified Wnt proteins. Cell Rep. 4, 1072-81.

Rivera, R.M. \& Hansen, P.J. (2001). Development of cultured bovine embryos after exposure to high temperatures in the physiological range. Reproduction 121, 107-15.

Robinson, M.D. \& Cistola, D.P. (2014). Nanofluidity of fatty acid hydrocarbon chains as monitored by benchtop timedomain nuclear magnetic resonance. Biochemistry 53, 751522.

Salehi, R., Colazo, M.G., Oba, M. \& Ambrose, D.J. (2015). A prepartum diet supplemented with oilseeds high in oleic or linoleic acid reduced GnRH-induced LH release in dairy cows during second week postpartum. Reprod. Biol. Endocrinol. 13, 69.

Shaaker, M., Rahimipour, A., Nouri, M., Khanaki, K., Darabi, M., Farzadi, L., Shahnazi, V. \& Mehdizadeh, A. (2012). Fatty acid composition of human follicular fluid phospholipids and fertilization rate in assisted reproductive techniques. Iran. Biomed. J. 16, 1-7.

Shehab-El-Deen, M.A., Leroy, J.L.M.R., Maes, D. \& Van Soom, A. (2009). Cryotolerance of bovine blastocysts is affected by oocyte maturation in media containing palmitic or stearic acid. Reprod. Domest. Anim. 44, 140-2.

Silvestre, F.T., Carvalho, T.S.M., Crawford, P.C., Santos, J.E.P., Staples, C.R., Jenkins, T. \& Thatcher, W.W. (2011). Effects of differential supplementation of fatty acids during the peripartum and breeding periods of Holstein cows: II. Neutrophil fatty acids and function, and acute phase proteins. J. Dairy Sci. 94, 2285-301.

Sinclair, K.D., Lunn, L.A., Kwong, W.Y., Wonnacott, K., Linforth, R.S.T. \& Craigon, J. (2008). Amino acid and fatty acid composition of follicular fluid as predictors of invitro embryo development. Reprod. Biomed. Online 16, 85968.

Stinshoff, H., Wilkening, S., Hanstedt, A., Bollwein, H. \& Wrenzycki, C. (2014). Dimethylsulfoxide and conjugated linoleic acids affect bovine embryo development in vitro. Reprod. Fertil. Dev. 26, 502-10.
Ströhle, A. \& Döring, F. (2010). Molecularization in nutritional science: a view from philosophy of science. Mol. Nutr. Food Res. 54, 1385-404.

Sudano, M.J., Santos, V.G., Tata, A., Ferreira, C.R., Paschoal, D.M., Machado, R., Buratini, J., Eberlin, M.N. \& LandimAlvarenga, F.D.C. (2012). Phosphatidylcholine and sphingomyelin profiles vary in Bos taurus indicus and Bos taurus taurus in vitro- and in vivo-produced blastocysts. Biol. Reprod. 87, 130.

Tabernero, A., Lavado, E.M., Granda, B., Velasco, A. \& Medina, J.M. (2001). Neuronal differentiation is triggered by oleic acid synthesized and released by astrocytes. J. Neurochem. 79, 606-16.

Tepekoy, F., Ustunel, I. \& Akkoyunlu, G. (2014). Protein kinase $C$ isoforms $\alpha, \delta$ and $\varepsilon$ are differentially expressed in mouse ovaries at different stages of postnatal development. J. Ovarian Res. 7, 1-11.

Uzbekova, S., Elis, S., Teixeira-Gomes, A.-P., Desmarchais, A., Maillard, V. \& Labas, V. (2015). MALDI mass spectrometry imaging of lipids and gene expression reveals differences in fatty acid metabolism between follicular compartments in porcine ovaries. Biology (Basel). 4, 216-36.

Valckx, S.D.M., Arias-Alvarez, M., De Pauw, I., Fievez, V., Vlaeminck, B., Fransen, E., Bols, P.E.J. \& Leroy, J.L.M.R. (2014a). Fatty acid composition of the follicular fluid of normal weight, overweight and obese women undergoing assisted reproductive treatment: a descriptive cross-sectional study. Reprod. Biol. Endocrinol. 12, 13.

Valckx, S.D.M., De Bie, J., Michiels, E.D., Goovaerts, I.G., Punjabi, U., Ramos-Ibeas, P., Gutierrez-Adan, A., Bols, P.E. \& Leroy, J.L. (2015). The effect of human follicular fluid on bovine oocyte developmental competence and embryo quality. Reprod. Biomed. Online 30, 203-7.

Valckx, S.D.M., Van Hoeck, V., Arias-Alvarez, M., Maillo, V., Lopez-Cardona, A.P., Gutierrez-Adan, A., Berth, M., Cortvrindt, R., Bols, P.E.J. \& Leroy, J.L.M.R. (2014b). Elevated non-esterified fatty acid concentrations during in vitro murine follicle growth alter follicular physiology and reduce oocyte developmental competence. Fertil. Steril. 102, 1769-76.

Van Hoeck, V., Bols, P.E.J., Binelli, M. \& Leroy, J.L.M.R. (2014). Reduced oocyte and embryo quality in response to elevated non-esterified fatty acid concentrations: A possible pathway to subfertility? Anim. Reprod. Sci. 149, 1929.

Van Hoeck, V., Leroy, J.L.M.R., Alvarez, M.A., Rizos, D., Gutierrez-Adan, A., Schnorbusch, K., Bols, P.E.J., Leese, H.J. \& Sturmey, R.G. (2013). Oocyte developmental failure in response to elevated nonesterified fatty acid concentrations: Mechanistic insights. Reproduction 145, 3344.

Van Hoeck, V., Sturmey, R.G., Bermejo-Alvarez, P., Rizos, D., Gutierrez-Adan, A., Leese, H.J., Bols, P.E.J. \& Leroy, J.L.M.R. (2011). Elevated non-esterified fatty acid concentrations during bovine oocyte maturation compromise early embryo physiology. PLoS One 6, e23183.

Vanholder, T., Leroy, J.L.M.R., Van Soom, A., Opsomer, G., Maes, D., Coryn, M. \& de Kruif, A. (2005). Effect of non-esterified fatty acids on bovine granulosa cell steroidogenesis and proliferation in vitro. Anim. Reprod. Sci. 87, 33-44. 
Vanholder, T., Lmr Leroy, J., Van Soom, A., Maes, D., Coryn, M., Fiers, T., de Kruif, A. \& Opsomer, G. (2006). Effect of non-esterified fatty acids on bovine theca cell steroidogenesis and proliferation in vitro. Anim. Reprod. Sci. 92, 51-63.

Vilella, F., Ramirez, L.B. \& Simón, C. (2013a). Lipidomics as an emerging tool to predict endometrial receptivity. Fertil. Steril. 99, 1100-6.

Vilella, F., Ramirez, L., Berlanga, O., Martínez, S., Alamá, P., Meseguer, M., Pellicer, A. \& Simón, C. (2013b). PGE2 and PGF $2 \alpha$ concentrations in human endometrial fluid as biomarkers for embryonic implantation. J. Clin. Endocrinol. Metab. 98, 4123-32.

Wang, G. \& Tsujii, H. (1999). Metabolism of exogenous palmitic and oleic acids by preimplantation mouse embryos. J. Mamm. Ova Res. 16, 10-5.

Warzych, E., Cieslak, A., Madeja, Z.E., Pawlak, P., Wolc, A. \& Lechniak, D. (2014). Multifactorial analysis of the follicular environment is predictive of oocyte morphology in cattle. J. Reprod. Dev. 60, 1-8.

Warzych, E., Pawlak, P., Pszczola, M., Cieslak, A. \& Lechniak, D. (2017). Prepubertal heifers versus cows - the differences in the follicular environment. Theriogenology 87, 36-47.

Wathes, D.C., Abayasekara, D.R.E. \& Aitken, R.J. (2007). Polyunsaturated fatty acids in male and female reproduction. Biol. Reprod. 77, 190-201.
Yahia Khandoker, M.A.M., Tsujii, H. \& Karasawa, D. (1998). A kinetics study of fatty acid composition of embryos, oviductal and uterine fluids in the rabbit. Asian Australas. J. Anim. Sci. 11, 60-4.

Yenuganti, V.R., Viergutz, T. \& Vanselow, J. (2016). Oleic acid induces specific alterations in the morphology, gene expression and steroid hormone production of cultured bovine granulosa cells. Gen. Comp. Endocrinol. 232, 134-44.

Zelinski, M.B., Selivonchick, D.P. \& Stormshak, F. (1988). Characterization of plasma membrane lipids and luteinizing hormone receptors of ovine corpora lutea during luteolysis and early pregnancy. Biol. Reprod. 38, 768-79.

Zeron, Y., Ocheretny, A., Kedar, O., Borochov, A., Sklan, D. \& Arav, A. (2001). Seasonal changes in bovine fertility: Relation to developmental competence of oocytes, membrane properties and fatty acid composition of follicles. Reproduction 121, 447-54.

Zeron, Y., Tomczak, M., Crowe, J. \& Arav, A. (2002). The effect of liposomes on thermotropic membrane phase transitions of bovine spermatozoa and oocytes: Implications for reducing chilling sensitivity. Cryobiology 45, 143-52.

Ziecik, A.J., Waclawik, A. \& Bogacki, M. (2008). Conceptus signals for establishment and maintenance of pregnancy in pigs - lipid signaling system. Exp. Clin. Endocrinol. Diabetes 116, 443-9. 